\title{
Frequency control of microgrid system based renewable generation using fractional PID controller
}

\author{
Regad Mohamed ${ }^{1}$, M. Helaimi ${ }^{2}$, R. Taleb ${ }^{3}$, Hossam A. Gabbar ${ }^{4}$, Ahmed M. Othman ${ }^{5}$ \\ ${ }_{1,2,3}$ Electrical Engineering Department, Hassiba Benbouali University, Alegria \\ ${ }^{4}$ Faculty of Energy Systems and Nuclear Science, and Faculty of Engineering and Applied Science, University of Ontario \\ Institute of Technology (UOIT), Canada \\ ${ }^{5}$ Electrical Power and Machine Department, Zagazig University, Egypt
}

\begin{tabular}{l}
\hline Article Info \\
\hline Article history: \\
Received Jan 10, 2020 \\
Revised Mar 11, 2020 \\
Accepted Mar 25, 2020 \\
\hline Keywords: \\
FOPID controller \\
Frequency regulation \\
Genetic algorithm \\
Krill Herd \\
Microgrid
\end{tabular}

\begin{abstract}
This paper addresses a control frequency scheme of the microgrid system using a fractional order PID controller. The proposed Microgrid system is consisted of a Photovoltaic System, Wind Turbine Generator, Diesel Engine Generator, Fuel Cell, and different storage systems like Battery Energy Storage Systems, and Flywheel Energy Storage Systems. The principal objective of the present paper is to limit the frequency and power deviations by the application of the proposed controller which has five parameters to be determined through optimization techniques. Krill Herd algorithm is used for determining the optimum fractional order PID controller parameters using the Integral of Squared Error. A comparison between the Genetic Algorithm and Krill Herd is done, and the obtained simulation results presents that the investigated controller-based Krill Herd outperforms the Genetic Algorithm in terms of fewer fluctuations in power and frequency deviation.
\end{abstract}

Copyright $(2020$ Institute of Advanced Engineering and Science. All rights reserved.

\section{Corresponding Author:}

Hossam A. Gabbar,

Faculty of Energy Systems and Nuclear Science,

University of Ontario Institute of Technology (UOIT),

2000 Simcoe St. N., Oshawa ON L1H 7K4 ON, Canada.

Email: Hossam.Gaber@uoit.ca

\section{INTRODUCTION}

Today the system control and stability are leading greater interest in the use of microgrid. Renewable Energy Sources are the energy produced by natural sources such as wind, sunlight, rain, lids and geothermal heat which are mostly used in power generation [1]. Renewable energy generation like wind and photovoltaic are the most important sources because of the depletion of fossil sources in the future and the greenhouse caused by gas emissions which have a dangerous effect on the environment situation. Renewable energy resources (RES) lead to reduce the focus on the use of fossil fuel sources [2-3].

Recently the frequency regulation is considered a big challenge related to using the microgrid system, due to the microgrid complexity, structure, and emergence of stochastic renewable energy sources. Frequency and power system stability is noted as an important problem in an electrical microgrid. The Microgrid system comprises two renewable sources like a wind turbine generator (WTG), solar generation, fuel cell (FCS), diesel engine generator (DEG), Battery Energy Storage Systems (BESS) and Flywheel Energy Storage Systems (FESS). The FESS is being selected for its efficiency and the shorttime response [4-5]. The microgrid can either operated in two modes interconnected or isolated from the utility grid. The advantage of the microgrid system is its suitability for providing the energy demand in the rural and isolated areas and helping the main grid in the connected model [6]. Unbalance between generation and load provokes the fluctuation of the system frequency and power which results in some control difficulties. 
The power and frequency fluctuation is a serious problem related to the hybrid system which imposes the search for efficient regulation. This can be realized by the use of modern controllers such as the Fractional PID controller [7-8]. The load frequency regulation is considered as the important control issue related to the microgrid system, conception, and operation. However, if it connected to the utility grid it becomes difficult to control fluctuation in the system frequency. The primary control is not able to the regulated frequency in the presence of integration of renewable sources then this requires the use of storage devices and supplementary control strategies. For resolving the power and frequency fluctuations issue, the Fractional Order controller employed in feedback [9]. A fractional Order -Proportional-integralderivation (FOPID) controller is applied to regulate the frequency of the microgrid system as in the previous works [7-8] use the Genetic Algorithm and Particle Swarm Optimization to determine the controller's parameters. It presents important flexibility to control the system frequency fluctuations through five parameters. It has been illustrated that fractional order PID is the better control performances [10-12]. Robust optimization techniques like GA and PSO have been investigated to optimize the FOPID controller parameters for frequency control in microgrid [7-8, 12-14].

In this work, the Krill Herd technique is used and defined as a stochastic and powerful optimization method that can be the best tool to solve complex optimization problems and it is not yet applied to optimize the gain of the proposed controller scheme. The FOPID-based Krill Herd is compared to FOPID using the Genetic algorithm. The robustness against the system parameters change and Ultracapacitor disconnecting is tested and the obtained results show that the KH based FOPID controller outperforms FOPID based GA to improve the system performances and reduce the fluctuation in power and frequency deviations. The rest of this paper can be outlined as a fellow; the Microgrid system model is presented in Section 2. In Section 3 the controller structure and optimization technique are reported. The results and discussions are addressed in Section 4. This paper is finished by a conclusion in Section 5 followed by references.

\section{MICROGRID SYSTEM MODELLING}

This system consists of WTG, PV, DEG, FC, battery, and flywheel [15-16]. The integration of the energy storage system is necessary for a hybrid isolated microgrid model to realize both functions of storage and releasing energy in a short time. The surplus of generated power from the photovoltaic system and wind generator is stored in the battery and flywheel system to be sent later to the load. Furthermore, when the principal's renewable energy sources are enabling to produce the requested power, the supplementary generator such as Diesel generator and fuel cell begins to fill the gap in generated power [17]. FOPID controllers based $\mathrm{KH}$ is integrated into the hybrid system to reduce the unbalance between the total produced power and load to keep the frequency deviation well within the limit. The different models of microgrid components are shown in Figure 1.

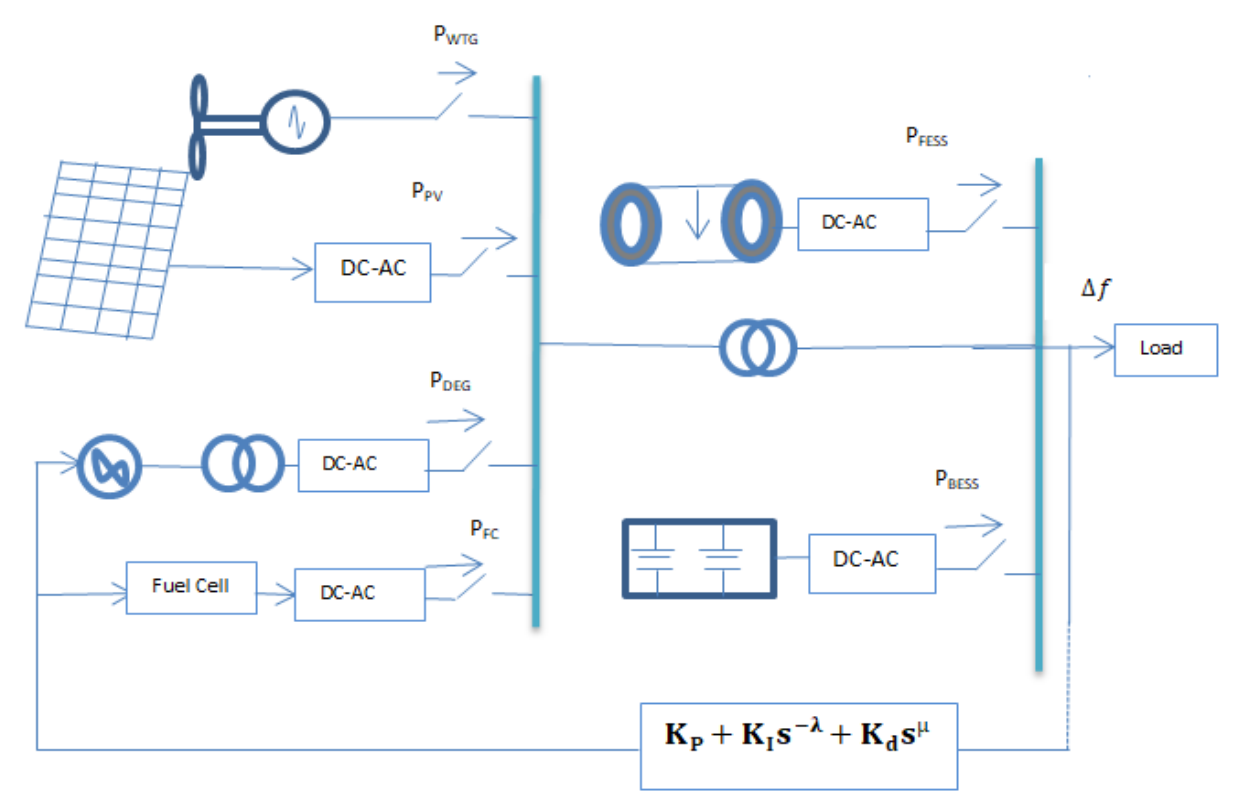

Figure 1. Schematic of the Microgrid system with energy storage and regeneration compounds 


\subsection{Models of various generation subsystem}

The various generators such as WTG, DEG, SPG, and FC can be modelled by the first-order transfer function (1-4) with its gain and time constants in Table 1 [5,7-8,17].

$$
\begin{aligned}
& G_{W T G}=\frac{K_{W T G}}{1+S T_{W T G}}=\frac{\Delta P_{W T G}}{\Delta P_{W}} \\
& G_{P V}=\frac{K_{P V}}{1+S T_{P V}}=\frac{\Delta P_{P V}}{\Delta \emptyset} \\
& G_{F C}=\frac{K_{F C}}{1+S T_{F C}}=\frac{\Delta P_{F C}}{\Delta u} \\
& G_{D E G}=\frac{K_{F C}}{1+S T_{D E G}}=\frac{\Delta P_{D E G}}{\Delta u}
\end{aligned}
$$

Table 1. Parameters of the proposed hybrid system

\begin{tabular}{ccc}
\hline Component & Gain $(\mathrm{K})$ & Time constant $\mathrm{T}(\mathrm{s})$ \\
\hline Wind Turbine Generator & $\mathrm{K}_{\mathrm{WTG}}=1$ & $\mathrm{~T}_{\mathrm{WTG}}=1.5$ \\
Photovoltaic Generator & $\mathrm{K}_{\mathrm{PV}}=1$ & $\mathrm{~T}_{\mathrm{PV}}=1.8$ \\
Fuel Cell (FC) & $\mathrm{K}_{\mathrm{FC}}=0.01$ & $\mathrm{~T}_{\mathrm{FC}}=4$ \\
Diesel engine generator & $\mathrm{K}_{\mathrm{DEG}}=0.003$ & $\mathrm{~T}_{\mathrm{DEG}}=2$ \\
Battery energy storage system & $\mathrm{K}_{\mathrm{BESS}}=-0.003$ & $\mathrm{~T}_{\mathrm{BESS}}=0.1$ \\
Flywheel energy storage system & $\mathrm{K}_{\mathrm{FESS}}=-0.01$ & $\mathrm{~T}_{\mathrm{FESS}}=0.1$ \\
\hline
\end{tabular}

\subsection{Models of different storage systems}

The storage energy system is a significant device in the hybrid system, to store the fluctuation of generated power to release it to supply the connected load where there is an unbalance between generation and load. The transfer functions of the BESS and FESS can be, respectively, presented as first-orders given next [5,7-8,17-18].

$$
\begin{aligned}
& \mathrm{G}_{\mathrm{BESS}}=\frac{\mathrm{K}_{\mathrm{BESS}}}{1+\mathrm{ST}_{\mathrm{BESS}}}=\frac{\Delta \mathrm{P}_{\mathrm{BESS}}}{\Delta \mathrm{u}} \\
& \mathrm{G}_{\mathrm{FESS}}=\frac{\mathrm{K}_{\mathrm{FESS}}}{1+\mathrm{ST}_{\mathrm{FESS}}}=\frac{\Delta \mathrm{P}_{\mathrm{FESS}}}{\Delta \mathrm{u}}
\end{aligned}
$$

\subsection{Model of power system}

To maintain the hybrid system stable, the power fluctuation required to be controlled. This strategy regulation expressed using the difference between the demand power reference PL and total power generation Ps as follows:

$$
\Delta \mathrm{P}=\mathrm{PL}-\mathrm{Ps}
$$

The system frequency deviation varies with the power variation; hence the system frequency deviation can be determined by $(8)[5,7-8]$.

$$
\Delta \mathrm{f}=\frac{\Delta \mathrm{P}}{\mathrm{K}}
$$

Where $\mathrm{K}$ is the system frequency characteristic constant and $\Delta \mathrm{P}$ is the variation of generating power. The power system model can be presented by $(9)[5,10,12]$

$$
\mathrm{G}_{\text {syst }}=\frac{\Delta \mathrm{f}}{\Delta \mathrm{P}}=\frac{1}{\mathrm{~K}(1+\mathrm{T})}=\frac{1}{\mathrm{D}+\mathrm{Ms}}
$$

Where $\mathrm{D}$ and $\mathrm{M}$ are respectively the damping's constant and the equivalent of the hybrid system inertia constant, with $\mathrm{D}=0.012$ and $\mathrm{M}=0.2$ for present simulation $[10,12]$. 


\subsection{A stochastic model of renewable energy and loads}

Small stochastic power fluctuation and large deterministic drift reckoning for solar generation, wind generation, and load demand can be modeled in the general template chosen as $(10)[10,12]$.

$$
P=\left(\frac{\varphi \cdot \eta \cdot \sqrt{\beta} \cdot(1-G(s))+\beta}{\beta}\right) \cdot \Gamma=\Gamma \cdot \chi
$$

Where $\phi$ is the stochastic component of the power, $\mathrm{P}$ shows the produced power from wind or solar and load demand power, $\beta$ contributes to the mean value of the power, $\eta$ is constant to normalize the generated or demand powers $(\chi)$ to match the per unit (p.u.) level, $\Gamma$ is a time-dependent switching signal with a gain which dictates the sudden fluctuation in the main value for the power output [10, 12]. For the parameters of the generated power of the wind system is:

$$
\begin{aligned}
& \varphi \sim U(-1,1), \eta=0.8, \beta=10, G(s)=\frac{1}{10^{4} . s+1} \\
& \text { and } \\
& \Gamma=0.24 h(t)-0.04 h(t-140)
\end{aligned}
$$

Where $\mathrm{h}(\mathrm{t})$ is the Heaviside step function.

For the solar power generation, the parameters of (10) are:

$$
\varphi \sim U(-1,1), \eta=0.9, \beta=10, G(s)=\frac{1}{10^{4} . s+1}
$$

and,

$$
\Gamma=0.05 \mathrm{~h}(\mathrm{t})+0.02 \mathrm{~h}(\mathrm{t}-180)
$$

For the demand load, the parameters of (10) are:

$$
\begin{aligned}
& \varphi \sim \mathrm{U}(-1,1), \eta=0.8, \beta=10, \\
& \mathrm{G}(\mathrm{s})=\frac{300}{300 . \mathrm{s}+1}+\frac{1}{1800 . \mathrm{s}+1}
\end{aligned}
$$

And,

$$
\begin{aligned}
& \quad \Gamma=\frac{1}{\chi}[0.9 h(t)+0.03 h(t-110)+0.03 h(t-130)+0.03 h(t-150)-0.15 h(t-170)+ \\
& 0.1 h(t-190)]+0.02 h(t)
\end{aligned}
$$

\section{FRACTIONAL ORDER PID CONTROLLER AND OPTIMIZATION TECHNIQUE}

\subsection{Fractional PID controller}

A Fractional Order PID controller is a suitable controller design with $\lambda$ and $\mu$ are the integral and derivative order. This originated from the fact that the PID controller has three parameters to be optimized, while the fractional PID controller has five parameters [7-12]. These additional parameters work to enhance the system efficiency and could lead to more robust control performances, more adequate modeling and add more flexibility to controller design. FOPID can control many real-world processes more accurately [19-20]. A FOPID can be presented in the Laplace domain is given by [21].

$$
C(s)=K_{P}+K_{I} s^{-\lambda}+K_{d} s^{\mu} \lambda, \mu \in R+
$$

Where $\mathrm{C}(\mathrm{S})$ is controller output,

$\mathrm{Kp}$ is proportional constant gain,

$\mathrm{Ki}$ is integration constant gain,

$\mathrm{Kd}$ is derivative constant gain,

$\lambda$ is Order of integration 
$\mu$ is the Order of the differentiator.

When taking $\lambda=\mu=1$ the result is the classical PID controller.

\subsection{Objective function}

For the effective operating of the hybrid system, the fractional PID controller parameters need to be determined. To overcome this issue, an objective function in (15) is used to minimize the frequency deviation $(\Delta \mathrm{f})$ in addition to the control signal $(\Delta \mathrm{u})$. ISE (Integral of Squared Error) is used as a fitness function to tuning the controller parameters. The fitness function has been defined as an integration between the Tmin and Tmax simulation period, using the sum of square frequency deviation $(\Delta \mathrm{f})$ and the deviation of the control signal $(\Delta \mathrm{u})[10,12]$.

$$
\mathrm{J}=\int_{\mathrm{T}_{\min }}^{\mathrm{T}_{\max }}\left[\mathrm{w}(\Delta \mathrm{f})^{2}+\left(\frac{1-\mathrm{w}}{\mathrm{Kn}}\right)(\Delta \mathrm{u})^{2}\right] \mathrm{dt}
$$

Where w represents the Integral of Square Error (ISE) of frequency deviation and the Integral of Squared Deviation of Controller Output (ISDCO), and its value is taken as $0.7 . K n=10^{4}$ is a constant to normalize to tabulate ISE and ISDCO in uniform stagger [12].

\subsection{Krill herd algorithm}

\subsubsection{Concept}

A new optimization method known as Krill Herd $(\mathrm{KH})$ optimization technique based on simulating the behavior of Krill individuals in Krill herd using for resolving complicated optimization problems was designed by [22]. The minimum distance taken by the Krill to food and the density of here is the objective of the movement. This Algorithm is considered as a metaheuristics optimization technique. The objective function of the krill motion is mostly affected by the herd density and the own distances of individual krill to food. The time position of a Krill individual is determined according to the movement made by other Krill, the rummaging for provisions and the random diffusion [22].

\subsubsection{KH description}

The individual krill proceeds toward the best position to the highest intensity and food. Krill individuals try to maintain high intensities and move toward the best solution. It is shown that an optimization method should be able to achieve research spaces of arbitrary dimensionality [23]. It can be formulated over time and for $\mathrm{N}$-dimensional space, using the bellowing Lagrangian model [24-25].

$$
\frac{d x_{i}}{d t}=N_{i}+F_{i}+D_{i}
$$

Where $N_{i}$ is the induced movement do by other Krill individuals, $F_{i}$ is the foraging motion and $D_{i}$ is the physical diffusion of the $i^{\text {th }}$ Krill individual [26].

The direction of $\mathrm{Ni}$ which is called c $\mathrm{i}$ is influenced by local position and density of the best krill. Ni is calculated with the following formula:

$$
\mathrm{N}_{\mathrm{i}}^{\text {new }}=\mathrm{N}^{\max } \alpha_{\mathrm{i}}+\omega_{\mathrm{n}} \mathrm{N}^{\text {old }}
$$

Where $N^{\max }$ is the maximum induced speed, and $\alpha_{i}$ is defined as:

$$
\alpha_{\mathrm{i}}=\alpha^{\text {local }}+\alpha^{\text {target }}
$$

$\omega_{n}$ is the inertia weight of the motion induced in the range [0,1], $N^{\text {old }}$ is the last motion-induced, $\alpha^{\text {local }}$ is the local effect provided by the neighbors and $\alpha^{\text {target }}$ is the target direction effect provided by the best krill individuals.

The Krill Herd Algorithm process can be presented in the flowchart shown by Figure 2. Further details about the Krill Herd optimization technique can be found in the literature as in [22]. The Krill Herd algorithm is a bio-inspired and swarm-based algorithm that can solve many complex optimization problems and outperform other metaheuristics algorithms. The $\mathrm{KH}$ algorithm can carefully simulate the krill behavior, and the values of these coefficients were determined using empirical studies in the real-world of krill systems. KH starts with the creation of an initial population of solution. For each solution, the fitness function is evaluated. 


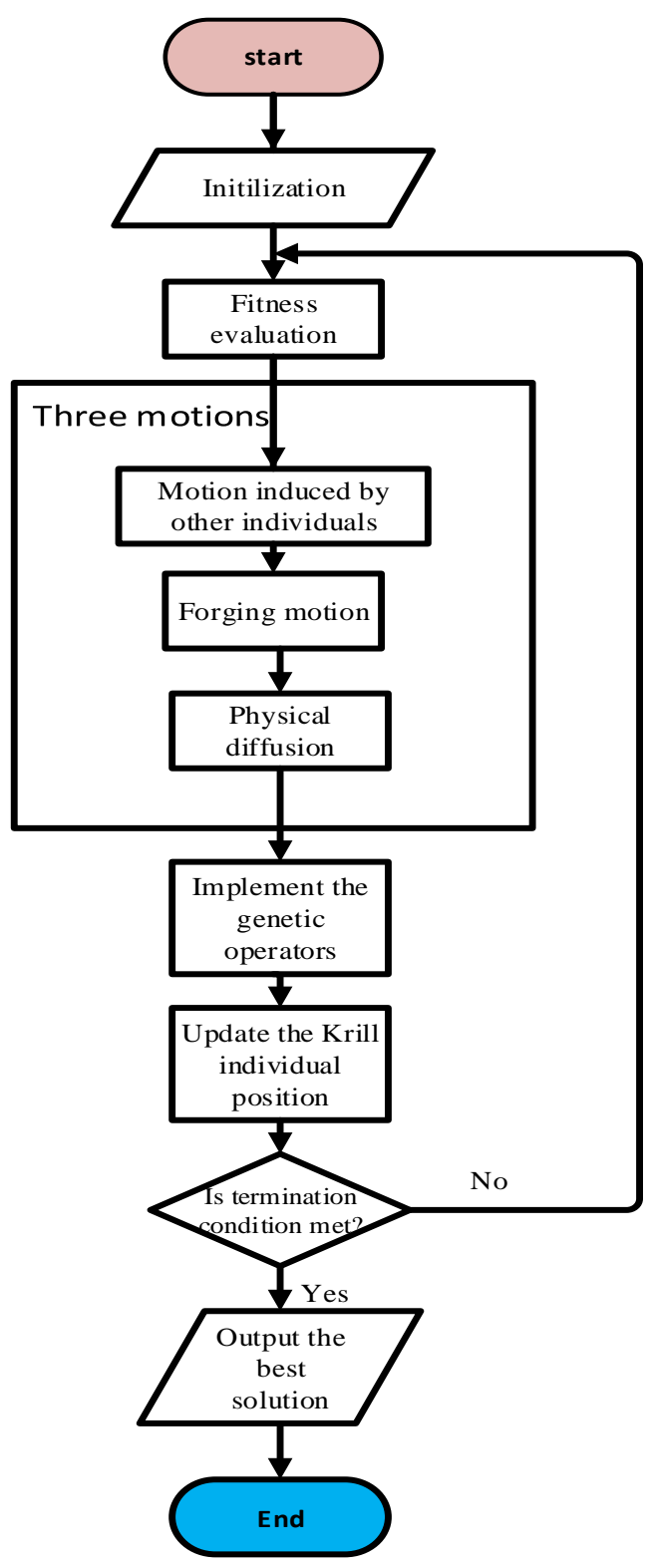

Figure 2. Flowchart of KH algorithm

\section{RESULTS AND DISCUSSIONS}

This section shows the different simulation results and discussions. The proposed system is simulated under nominal operation conditions with the integration of fraction Order PID controller optimized using GA and $\mathrm{KH}$ and the obtained results are reported and compared. It is also simulated under parameter variation and disconnection of energy storage device (ultra-capacitor) to test the robustness.

\subsection{Performance of the fractional Order PID controller using krill herd}

Such regulations try to reduce the system power fluctuation and frequency deviation. The hybrid power system is analyzed using the Fractional PID controller optimized by Krill Herd as described in Section 3 while the system is considered to be operating in a linear regime. The total simulation time is 200 seconds. It has been noted that the objective function have a stochastic nature because for the same gains value the fitness function varies for each simulation running. The KH has been run multiple times; the number of krill is increased to 30. The generated powers ( $\mathrm{Pw}, \mathrm{Psol})$, the net generated power to the grid (Pt) and also the demand $(\mathrm{Pl})$ is shown in Figure 3. These are stochastic components that are independent of the controller structure. 

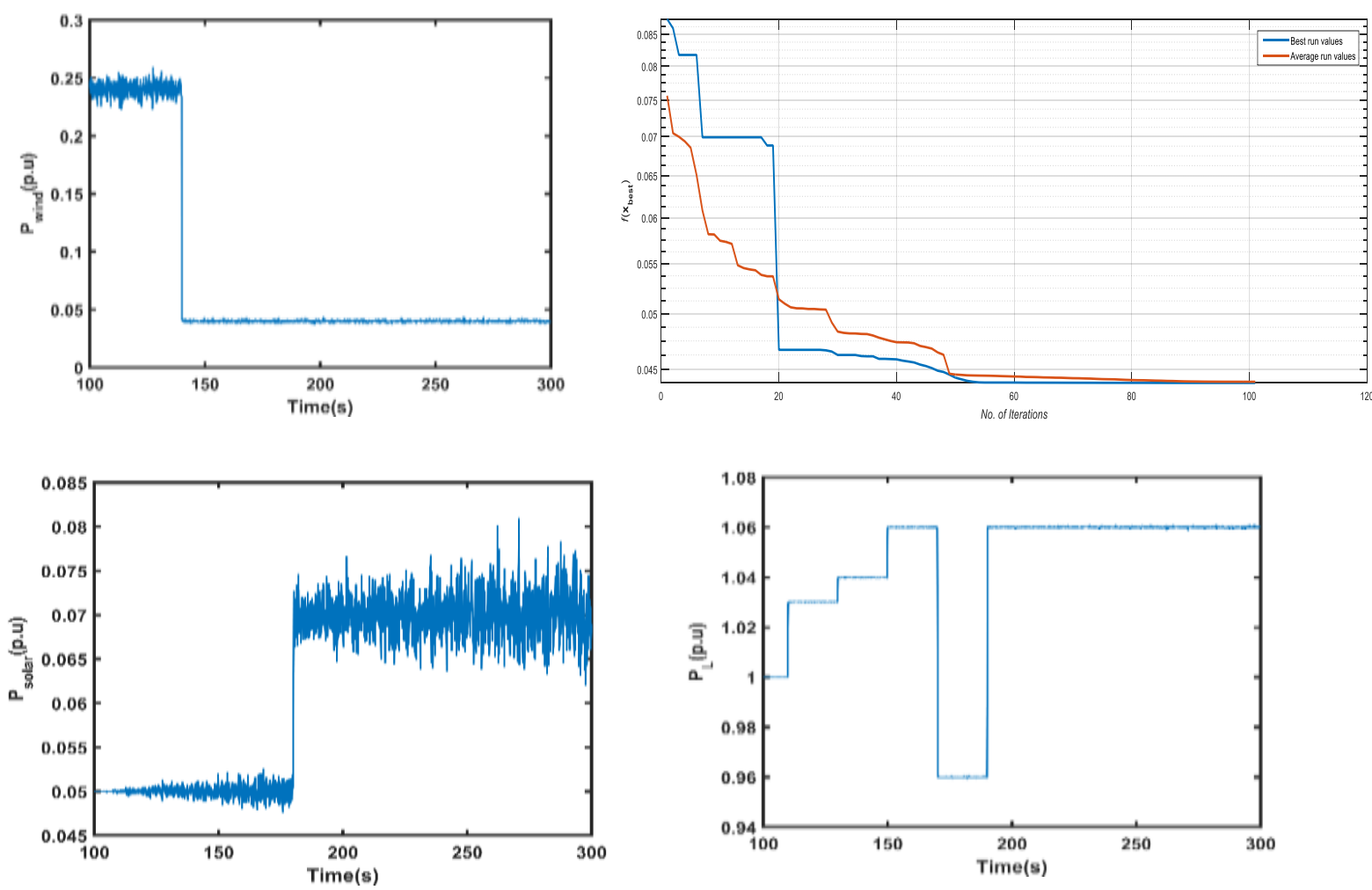

Figure 3. Stochastic generation and loads powers, independently of the controller scheme along with the convergence of Krill Herd

\subsection{Comparison between GA and KH based FOPID under the nominal operating conditions of the Microgrid}

This subsection presents different results of the comparison between the Genetic Algorithm and Krill herd based Fractional Order PID controller for frequency and power deviations control. The corresponding power and frequency deviations are reported in Figure 4. It can be remarked that there are fewer power variations with the FOPID controller-based Krill Herd than for GA. Thus it would be a better optimization tool in this case study of the microgrid. These sets of data are obtained by substituting the values of the controller parameters in the power system model. It can be shown that the system performances are more enhanced with the FOPID-KH than FOPID-GA.

Frequency and power deviation $(\Delta \mathrm{f}, \Delta \mathrm{P})$ for FOPID
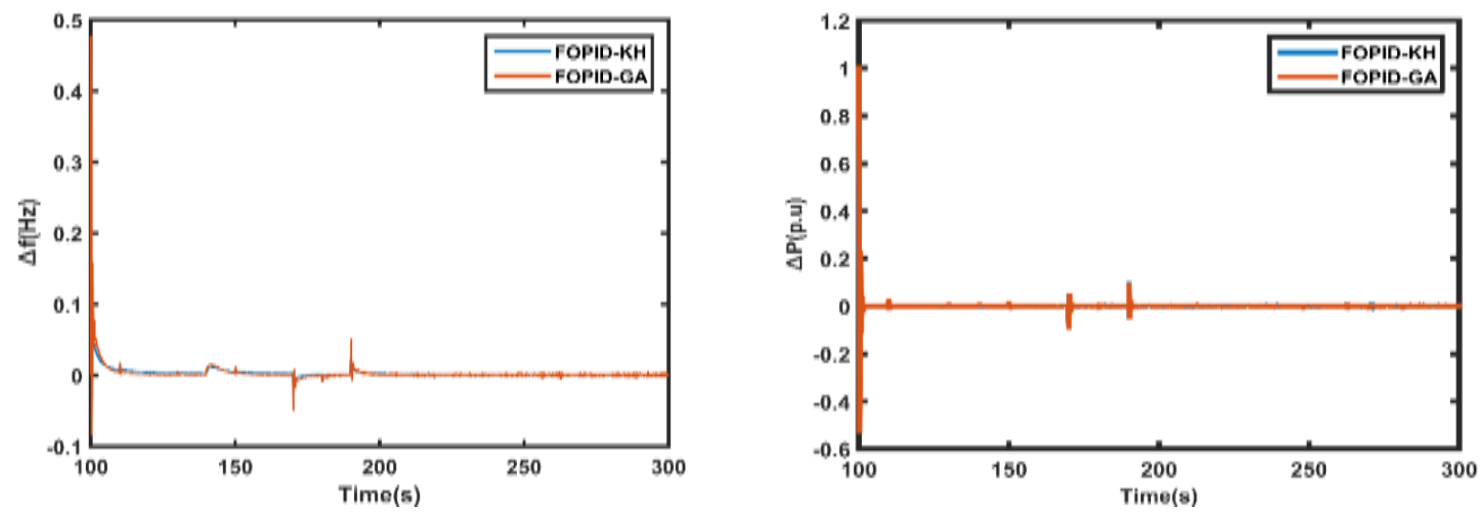

Figure 4. Frequency deviations and power deviation of microgrid with best obtained /FOPID controllers 


\subsection{Robustness against disconnecting the UC using FOPID based KH}

Due to the existence of stochastic terms in generation and load, the optimization of the parameters controller leads to eliminate the frequency and power deviation. The system is simulated with and without UC using the Krill Herd based FOPID to display the advantages of the fractional-order controllers, impact of these devices and suitability of optimization techniques. This focuses on the section of an objective function as in (15) to be resolved using $\mathrm{KH}$ while its variables are the gains of the controller. Figure 5 shows the corresponding powers generated by different components of microgrid with and without ultra-capacitor. The results presents that this device has a significant effect on the microgrid operation and state of power. This implies that the integration of these energy generation and storage devices can be reduced with the use of FOPID controller.
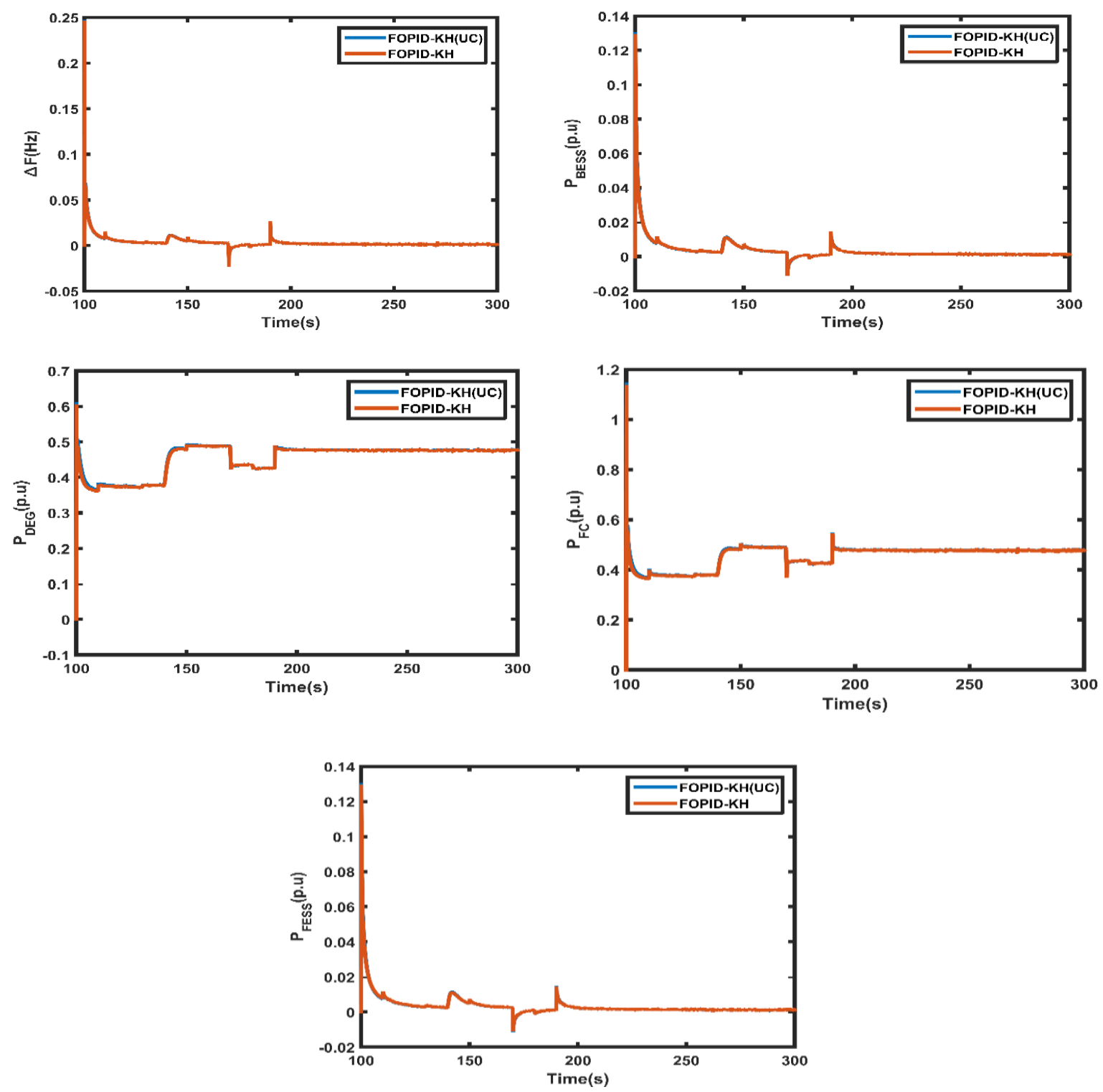

Figure 5. Frequency deviation and Generated power by different Microgrid components

\subsection{Robustness against the microgrid parameters variations using FOPID based KH and GA}

The system is simulated under perturbations in parameters for testing the robustness of the proposed fractional PID controller based Krill Herd and Genetic Algorithm against the parameters increase and decrease and the objective function values are reported in the followed Table 2. The obtained results are shown in the Figure 6. 
Table 2. Robustness against perturbation in microgrid parameters

\begin{tabular}{|c|c|c|c|c|}
\hline Microgrid parameters & Perturbations \pm & Controllers FOPID & $\mathrm{J}$ increase & $\mathrm{J}$ decrease \\
\hline & & KH & 0.0393 & 0.0392 \\
\hline \multirow[t]{2}{*}{$D$} & $70 \%$ & GA & 0.05093 & 0.05091 \\
\hline & & $\mathrm{KH}$ & 0.03931 & 0.03929 \\
\hline \multirow[t]{2}{*}{$T_{F C}$} & $20 \%$ & GA & 0.05093 & 0.05092 \\
\hline & & $\mathrm{KH}$ & 0.03931 & 0.03928 \\
\hline \multirow[t]{2}{*}{$T_{g}$} & $70 \%$ & GA & 0.05093 & 0.05091 \\
\hline & & $\mathrm{KH}$ & 0.03931 & 0.03927 \\
\hline \multirow[t]{2}{*}{$T_{t}$} & $70 \%$ & GA & 0.05094 & 0.05091 \\
\hline & & $\mathrm{KH}$ & 0.0393 & 0.0393 \\
\hline \multirow[t]{2}{*}{$T_{I C}$} & $70 \%$ & GA & 0.05093 & 0.05093 \\
\hline & & $\mathrm{KH}$ & 0.03932 & 0.03928 \\
\hline \multirow[t]{2}{*}{$T_{I N}$} & $0.5 \%$ & GA & 0.05092 & 0.0509 \\
\hline & & $\mathrm{KH}$ & 0.03929 & 0.03992 \\
\hline \multirow[t]{2}{*}{$R$} & $70 \%$ & GA & 0.05092 & 0.05099 \\
\hline & & $\mathrm{KH}$ & 0.03929 & 0.03935 \\
\hline $2 \mathrm{H}$ & $50 \%$ & GA & 0.05089 & 0.0511 \\
\hline
\end{tabular}
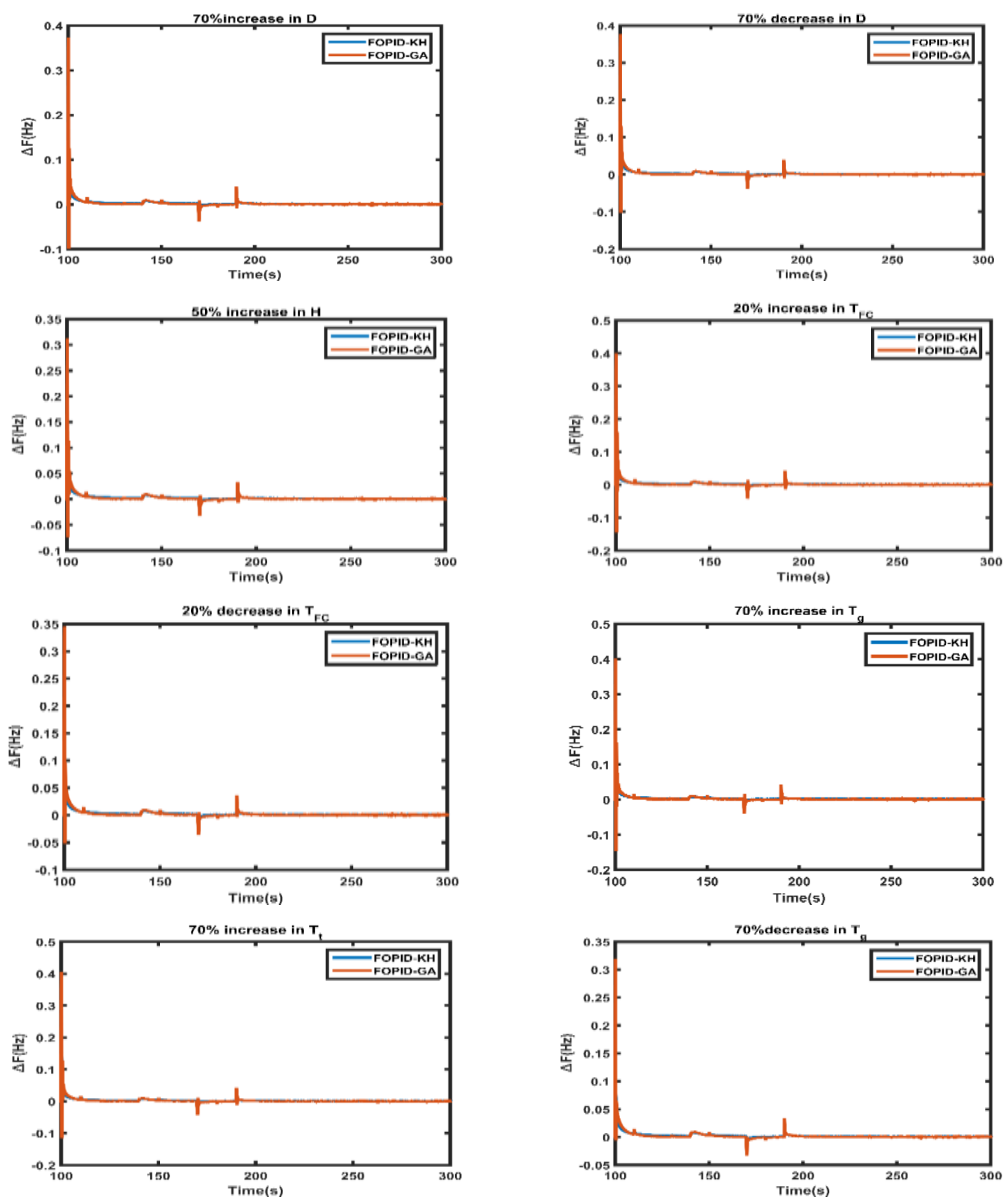

Frequency control of microgrid system based renewable generation using... (Regad Mohamed) 

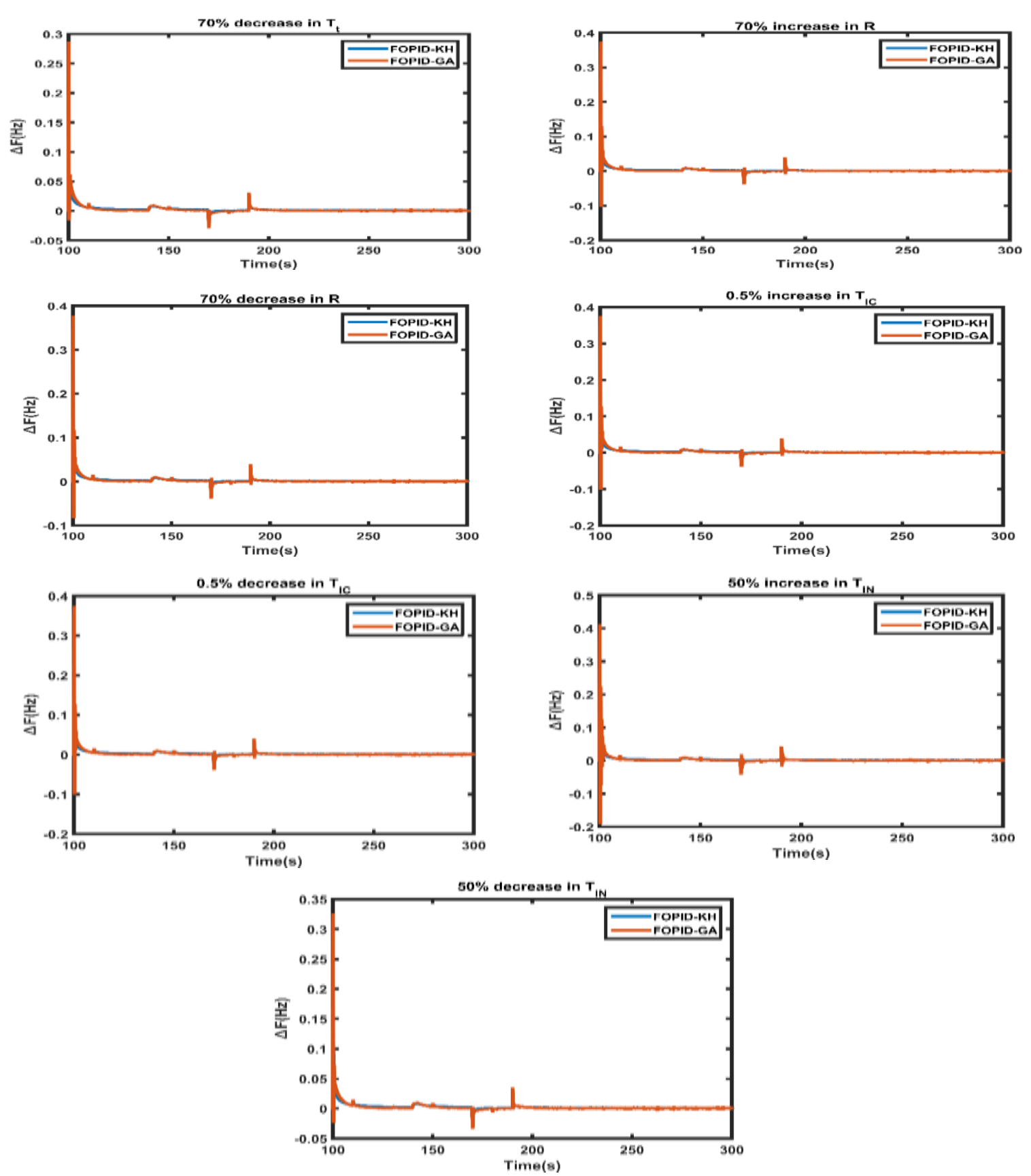

Figure 6. Frequency responses in microgrid parameters variations with best FOPID based KH and GA

\section{CONCLUSION}

The present paper investigates the application of fractional order controller eliminating the fluctuations of system frequency in a linear model of the microgrid with stochastic components in generation power and loads. The simulation results show that the standard Krill Herd gives the best performance in terms of faster convergence and quality of solution in comparison with the Genetic Algorithm. The centralized scheme offers a better regulation of frequency deviation and power fluctuation. It can be concluded that the FOPID controller-based Krill Herd (FOPID-KH) is better than the FOPID-GA controller using the nominal designing condition of operation and shows better robustness for large parametric uncertainty of the microgrid along with disconnection of ultracapacitor energy storage device. We have displayed simulations using the investigated system, and verify the availability efficiency of the Microgrid system. 


\section{REFERENCES}

[1] Alhamrouni, Ibrahim, et al., "Modeling of Micro-grid with the consideration of total harmonic distortion analysis," Indonesian Journal of Electrical Engineering and Computer Science, vol. 15, no. 2, pp. 581-592, 2019.

[2] Jeman, Ameerul Aiman Bin, Naeem MS Hannoon, and Ismail Misrin, "Small signal fault analysis for renewable energy (wind) power system distributed generation by using MATLAB software (simulink)," Indonesian Journal of Electrical Engineering and Computer Science, vol. 5, no. 3, pp. 401-408, 2017.

[3] De Souza Ribeiro, Luiz Antonio, et al., "Isolated micro-grids with renewable hybrid generation: The case of Lençóis Island," IEEE Transactions on sustainable energy, vol. 2, no. 1, pp. 1-11, 2011.

[4] Y. Kouba, et al., "Automatic generation control in interconnected power system with integration of wind power generation using PID based on particle swarm optimization," International Conference on Renewable Energies and Power Quality (ICREPQ'14), Cordoba (Spain), 2014.

[5] LEE Dong-Jing; WANG Li, "Small-signal stability analysis of an autonomous hybrid renewable energy power generation/energy storage system part I: Time-domain simulations," IEEE Transactions on Energy Conversion, vol. 23, no. 1, pp. 311-320, 2008.

[6] Khan, M. Reyasudin Basir, et al., "Optimal grid-connected PV system for a campus microgrid," Indonesian Journal of Electrical Engineering and Computer Science, vol. 12, no. 3, pp. 899-906, 2018.

[7] M. Regad, M. Helaimi, R. Taleb, H. A. Gabbar, and A. M. Othman, "Fractional order PID control of hybrid power system with renewable generation using genetic algorithm," 2019 IEEE 7th International Conference on Smart Energy Grid Engineering (SEGE), Oshawa, ON, Canada, pp. 139-144, 2019.

[8] PAN, Indranil; DAS, Saptarshi. "Fractional order fuzzy control of a hybrid power system with renewable generation using chaotic PSO," ISA transactions, vol. 62, pp. 19-29, 2016.

[9] Zhao, Chunna, Dingyu Xue, and YangQuan Chen, "A fractional order PID tuning algorithm for a class of fractional order plants," IEEE International Conference Mechatronics and Automation, vol. 1, 2005.

[10] I. Pan and S. Das, "Kriging based surrogate modeling for fractional-order control of microgrids," Smart Grid, IEEE Transactions on, vol. 6, no. 1, pp. 36-44, 2015.

[11] Swagatam Das, et al., "Design of fractional-order PI $\mu$ D $\lambda$ controllers with an improved differential evolution," Engineering Applications of Artificial Intelligence, vol. 22, no. 2, pp. 343-350, 2009.

[12] Pan, Indranil, and Saptarshi Das. "Fractional order AGC for distributed energy resources using robust optimization," IEEE transactions on smart grid, vol. 7, no. 5, pp. 2175-2186, 2015.

[13] Pan, Indranil, and Saptarshi Das, "Fractional-order load-frequency control of interconnected power systems using chaotic multi-objective optimization," Applied Soft Computing, vol. 29, pp. 328-344, 2015.

[14] Zamani, Majid, et al. "Design of a fractional order PID controller for an AVR using particle swarm optimization," Control Engineering Practice, vol. 17, no. 12, pp. 1380-1387, 2009.

[15] Tomonobu Senjyu, et al., "A hybrid power system using alternative energy facilities in isolated island," IEEE Transactions on Energy Conversion, vol. 20, no. 2, 406 - 414, 2005.

[16] Regad M., Helaimi M., Taleb R., Othman A.M., Gabbar H.A., "Frequency control in microgrid power system with renewable power generation using pid controller based on particle swarm optimization," In: Hatti M. (eds) Smart Energy Empowerment in Smart and Resilient Cities, ICAIRES 2019. Lecture Notes in Networks and Systems, Springer, Cham, vol. 102, pp.3-13. 2020.

[17] DAS, DulalCh, et al., "Genetic algorithm based PI controller for frequency control of an autonomous hybrid generation system," Proc. International Multi conference of engineers and Computer scientists, vol. 2, 2011.

[18] DAS, DulalCh, Roy, A. K., Sinha, N., "GA based frequency controller for solar thermal-diesel-wind hybrid energy generation/energy storage system," International Journal of Electrical Power \& Energy Systems, vol. 43, no. 1, pp. 262-27, 2012.

[19] Maiti, Deepyaman, Sagnik Biswas, and Amit Konar. "Design of a fractional order PID controller using particle swarm optimization technique," arXiv preprint arXiv:0810.3776, 2008.

[20] Singh, Amandeep, and Sathans Suhag. "Frequency regulation in an AC microgrid interconnected with thermal system employing multiverse-optimised fractional order-PID controller," International Journal of Sustainable Energy, pp. 1-13, 2019.

[21] Arya, Yogendra, "AGC of restructured multi-area multi-source hydrothermal power systems incorporating energy storage units via optimal fractional-order fuzzy PID controller," Neural Computing and Applications, vol. 31, no. 3 pp. 851-872, 2019.

[22] Gandomi, Amir Hossein, and Amir Hossein Alavi, "Krill herd: a new bio-inspired optimization algorithm," Communications in Nonlinear Science and Numerical Simulation, vol. 17, no. 12, pp. 4831-4845, 2012.

[23] Gandomi, Amir Hossein, et al., "Krill herd algorithm for optimum design of truss structures," International Journal of Bio-Inspired Computation, vol. 5, no. 5, pp. 281-288, 2013.

[24] Yaghoobi, Saber; Mojallali, Hamed, "Tuning of a PID controller using improved chaotic Krill Herd algorithm," Optik-International Journal for Light and Electron Optics, vol. 127, no. 11, pp. 4803-4807, 2016.

[25] Alikhani, A., Suratgar, A. A., Nouri, K., Nouredanesh, M., and Salimi, S., "Optimal PID tuning based on the Krill Herd optimization algorithm," In The 3rd International Conference on Control, Instrumentation, and Automation, pp. 11-15, 2013.

[26] Gandomi, Amir Hossein, et al., "Metaheuristic algorithms in modeling and optimization," Metaheuristic applications in structures and infrastructures, pp. 1-24, 2013. 